\title{
Video Article \\ High Throughput, Absolute Determination of the Content of a Selected Protein at Tissue Levels Using Quantitative Dot Blot Analysis (QDB)
}

\author{
Xiaoying $\mathrm{Qi}^{{ }^{1}}$, Yunyun Zhang ${ }^{2}$, Yuan Zhang ${ }^{1}$, Tianhui $\mathrm{Ni}^{3}$, Wenfeng Zhang ${ }^{2}$, Chunhua Yang ${ }^{1}$, Jia Mi ${ }^{1,4}$, Jiandi Zhang ${ }^{2,3}$, Geng Tian ${ }^{1}$ \\ ${ }^{1}$ Medicine and Pharmacy Research Center, Binzhou Medical University \\ ${ }^{2}$ Yantai Zestern Biotechnique Co. LTD \\ ${ }^{3}$ Precision Medicine research center, Binzhou Medical University \\ ${ }^{4}$ Department of Chemistry - BMC, Uppsala University \\ *These authors contributed equally
}

Correspondence to: Jiandi Zhang at Jiandi.zhang@zestern.net, Geng Tian at tiangeng@live.se

URL: https://www.jove.com/video/56885

DOI: doi:10.3791/56885

Keywords: Biochemistry, Issue 138, Quantitative Dot Blot analysis (QDB), immunoblot, high throughput, absolute determination, Elisa Analysis.

Date Published: 8/21/2018

Citation: Qi, X., Zhang, Y., Zhang, Y., Ni, T., Zhang, W., Yang, C., Mi, J., Zhang, J., Tian, G. High Throughput, Absolute Determination of the Content of a Selected Protein at Tissue Levels Using Quantitative Dot Blot Analysis (QDB). J. Vis. Exp. (138), e56885, doi:10.3791/56885 (2018).

\section{Abstract}

Lacking a convenient, quantitative, high throughput immunoblot method for absolute determination of the content of a specific protein at cellular and tissue level significantly hampers the progress in proteomic research. Results derived from currently available immunoblot techniques are also relative, preventing any efforts to combine independent studies with a large-scale analysis of protein samples. In this study, we demonstrate the process of quantitative dot blot analysis (QDB) to achieve absolute quantification in a high throughput format. Using a commercially available protein standard, we are able to determine the absolute content of capping actin protein, gelsolin-like (CAPG) in protein samples prepared from three different mouse tissues (kidney, spleen, and prostate) together with a detailed explanation of the experimental details. We propose the QDB analysis as a convenient, quantitative, high throughput immunoblot method of absolute quantification of individual proteins at the cellular and tissue level. This method will substantially aid biomarker validation and pathway verification in various areas of biological and biomedical research.

\section{Video Link}

The video component of this article can be found at https://www.jove.com/video/56885/

\section{Introduction}

Alongside with the exciting advancements in genomic research in the recent years, biomedical research field also witnesses the significant advancement in proteomic research. With increasing accumulation of biological data at both genomic and proteomic levels, using bioinformatic tools to analyze these data has become the focus of biomedical research in the perceivable future. Consequently, the success of bioinformatical research raises demand for more and better quality of data from the biological and biomedical research community, a task can only be achieved through technique advancement at genomic and proteomic levels.

Mass spectrometry (MS) and immunoblot analysis are two prevailing techniques of protein analysis presently. MS has dominated the proteomic research in the recent years to enable analysis of thousands of individual proteins simultaneously. The immunoblot-based techniques, including western blot and dot blot, on the other hand, have also played a significant role in the protein research even since its invention ${ }^{1,2,3,4,5}$. Enzyme linked immunosorbent assay (ELISA) $)^{5,6,7}$ and reverse phase protein microarray (RPPM) ${ }^{8,9}$ can be considered the high throughput format of immunoblot analysis. However, all these immunoassay methods, except ELISA, measure the relative expression level of a specific protein. The relative nature of these methods will become a real problem for population studies, as the analysis must be done at the same time, preventing any efforts to increase the pool size through multiple analyses. Furthermore, the results derived from these studies are only semi-quantitative, thus complicating any bioinformatics efforts in the data analysis. Meanwhile, although ELISA is well suited for high throughput absolute analysis of protein samples, this technique seems to meet challenges in complex environments such as cells or tissues because of its low binding capacity and multiplexing ${ }^{10}$.

We have developed an immunoblot method suitable for population studies with the key characteristics of being convenient, high throughput, quantitative, and suitable for absolute determination of protein content, and named this technique quantitative dot blot analysis (QDB) ${ }^{11}$. In this study, we present a detailed protocol for QDB analysis and demonstrate the method by determining the absolute protein content of a specific protein, CAPG, in three different mouse tissues including kidney, spleen, and prostate. We think that this detailed protocol well illustrates the feasibility and convenience of this method, and provide guidance on how to avoid the potential pitfalls in the practice of this method. 


\section{Protocol}

All animal procedures were carried out in line with Binzhou Medical University Animal Use Directive and approved by the ethical review board of Binzhou Medical University.

\section{Sample Preparation}

1. Take $50 \mathrm{mg}$ mouse tissue into a $1.5 \mathrm{~mL}$ Tube. Add $200 \mu \mathrm{L}$ lysis buffer (50 mM Hepes, pH 7.4, $137 \mathrm{mM} \mathrm{NaCl}, 5 \mathrm{mM}$ EDTA, $5 \mathrm{mM}$ EGTA, 1 $\mathrm{mM} \mathrm{MgCl}_{2}, 10 \mathrm{mM} \mathrm{Na}_{2} \mathrm{P}_{2} \mathrm{O}_{7}, 1 \%$ Triton X-100, 10\% glycerol), supplemented with protease and phosphatase inhibitors (100 mM NaF, $0.1 \mathrm{mM}$ phenylmethylsulfonyl fluoride, $5 \mu \mathrm{g} / \mathrm{mL}$ pepstatin, $10 \mu \mathrm{g} / \mathrm{mL}$ leupeptin, $5 \mu \mathrm{g} / \mathrm{mL}$ aprotinin).

2. Homogenize the tissue with a homogenizer for 1 min on ice.

3. Centrifuge for $10 \mathrm{~min}$ at $8000 \mathrm{xg}$ at $4{ }^{\circ} \mathrm{C}$.

4. Collect the supernatant into new tubes $(1.5 \mathrm{~mL})$ and take out $1 \mu \mathrm{L}$ for protein concentration assay with $\mathrm{BCA}$ kit. Note: All the commonly used lysis buffers for western blot analysis and Dot blot analysis can be used for QDB analysis.

\section{Determining the Specificity of Antibody}

1. Prepare sample lysates $(20 \mu \mathrm{g})$ in section 1.4 , IgG free BSA $(20 \mu \mathrm{g})$, standard protein $(600 \mathrm{pg})$, for western blot analysis. Note: IgG free BSA is used as a negative control and the standard protein is used as a positive control. The specificity of the antibody is demonstrated by showing one band of right size using the western blot analysis.

\section{Defining the Linear Range of the QDB Analysis}

1. Dissolve the standard protein with $\mathrm{ddH}_{2} \mathrm{O}$. Dilute the protein to a concentration of $1,200 \mathrm{pg} / \mathrm{\mu L}$.

2. Dilute the concentrated protein from the prepared samples in section 1.4 to $4 \mu \mathrm{g} / \mu \mathrm{L}$.

3. Dissolve the BSA with $\mathrm{ddH}_{2} \mathrm{O}$. Dilute the protein to a concentration of $1,200 \mathrm{pg} / \mu \mathrm{L}$ and $4 \mu \mathrm{g} / \mu \mathrm{L}$.

4. A series of dilution of standard protein and prepared samples were prepared with the guidance of Table 1 and Table 2.

5. Mix $10 \mu \mathrm{L}$ dilution standard protein or dilution prepared samples and $10 \mu \mathrm{L} 2 x$ loading buffer $(120 \mathrm{mM} \mathrm{Tris-HCl} \mathrm{pH} 6.8,20 \% \mathrm{Glycerol}, 4 \%$ SDS, $0.2 \%$ Bromphenol Blue, $200 \mathrm{mM}$ DTT) together.

\begin{tabular}{|c|c|c|c|c|c|c|}
\hline & $\begin{array}{l}S 1 \\
(0 p g / \mu l)\end{array}$ & $\mathrm{S} 2(33.3 \mathrm{pg} / \mu \mathrm{l})$ & $\begin{array}{l}\text { S3 } \\
(100 \mathrm{pg} / \mu \mathrm{l})\end{array}$ & $\begin{array}{l}\text { S3 } \\
(300 p g / \mu l)\end{array}$ & $\begin{array}{l}55 \\
(600 p g / \mu l)\end{array}$ & $\begin{array}{l}66 \\
(1200 \mathrm{pg} / \mu \mathrm{l})\end{array}$ \\
\hline $\begin{array}{l}\text { standard } \\
\operatorname{protein}(1200 \mathrm{pg} / \mu \mathrm{l})\end{array}$ & 0 & 1.39 & 4.17 & 12.5 & 25 & 50 \\
\hline $\begin{array}{l}\operatorname{lgG} \text { free BSA } \\
(4 \mathrm{pg} / \mu \mathrm{l})\end{array}$ & 50 & 48.61 & 45.83 & 37.5 & 25 & 0 \\
\hline total & 50 & 50 & 50 & 50 & 50 & 50 \\
\hline
\end{tabular}

Table 1. Dilution Scheme for standard protein curve.

\begin{tabular}{|c|c|c|c|c|c|c|}
\hline & $\begin{array}{l}\mathrm{X} 1 \\
(0 \mu \mathrm{g} / \mu \mathrm{l})\end{array}$ & $\begin{array}{l}\mathrm{X} 2 \\
(0.25 \mu \mathrm{g} / \mu \mathrm{l})\end{array}$ & $\begin{array}{l}\text { X3 } \\
(0.5 \mu \mathrm{g} / \mu \mathrm{l})\end{array}$ & \begin{tabular}{|l|}
$X 4$ \\
$(1 \mu g / \mu l)$
\end{tabular} & $\begin{array}{l}X 5 \\
(2 \mu g / \mu l)\end{array}$ & $\begin{array}{l}\text { X6 } \\
(4 \mu g / \mu l)\end{array}$ \\
\hline 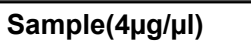 & 0 & 3.125 & 6.25 & 12.5 & 25 & 50 \\
\hline 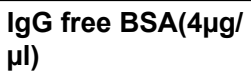 & 50 & 46.875 & 43.75 & 37.5 & 25 & 0 \\
\hline total & 50 & 50 & 50 & 50 & 50 & 50 \\
\hline
\end{tabular}

Table 2. Dilution Scheme for prepared samples

6. Heat the mixtures at $85^{\circ} \mathrm{C}$ for $5 \mathrm{~min}$.

\section{Process of QDB Analysis}

1. Sample application

1. Support the QDB plate to avoid the bottom of the plate touching the surface of the table. For instance, use an empty pipette tip box as support.

2. Load up to $2 \mu \mathrm{L}$ of the sample to the center of the membrane at the bottom of the individual unit of the QDB plate.

2. Drying the plate

1. Leave the loaded QDB plate for $1 \mathrm{~h}$ at room temperate $(\mathrm{RT})$ or as an alternative leave the loaded plate at $37^{\circ} \mathrm{C}$ for $15 \mathrm{~min}$ in a wellventilated space.

3. Blocking the plate 
1. Dip the QDB plate in the transfer buffer ( $0.039 \mathrm{M}$ Glycine, $0.048 \mathrm{M}$ Tris, $0.37 \% \mathrm{SDS}, 20 \%$ methyl alcohol) and gently shake the plate for $10 \mathrm{~s}$.

2. Rinse the QDB plate gently with TBST (Tris-buffered saline, $0.1 \%$ Tween 20) three times, and then wash the plate for 5 min in TBST under constant shaking.

3. Block the QDB plate with blocking buffer ( $5 \%$ nonfat milk in TBST ( $100 \mu \mathrm{L} /$ well) for $1 \mathrm{~h}$ under constant shaking.

\section{Primary antibody incubation}

1. Dilute the primary antibody in the blocking buffer at a chosen concentration (from 1: 500 to 1:5 000), and add $100 \mu \mathrm{L}$ to each individual well of an ordinary 96 well plate. Insert the QDB plate into the 96 well plate and incubate the combined plates either for $2 \mathrm{~h}$ at RT or overnight at $4{ }^{\circ} \mathrm{C}$ under constant shaking.

2. Alternatively, place the QDB plate inside a box, and fill the box with blocking buffer 2 to $3 \mathrm{~mm}$ above the membrane portion of the plate if the same antibody is used for the whole plate. Add the primary antibody at the chosen concentration, and incubate the plate either for $2 \mathrm{~h}$ at $\mathrm{RT}$ or overnight at $4^{\circ} \mathrm{C}$ by under constant shaking.

3. Rinse the plate gently with TBST for three times before it is washed with TBST for three times, each time for 5 min under constant shaking.

\section{Secondary Antibody incubation}

1. Dilute the secondary antibody in the blocking buffer at the chosen concentration (from 1:1, 000 to 1:50, 000), and either aliquot 100 $\mu \mathrm{L} /$ well into a 96 well plate or in a box as described in section 4.4.2, and then incubate the QDB plate inside either the loaded 96 well plate or the box for $1 \mathrm{~h}$ at $\mathrm{RT}$ under constant shaking.

2. Rinse the QDB plate gently 3 times with TBST, then wash the plate for 3 times, 5 min each with TBST under constant shaking.

\section{Quantification}

1. Prepare enhanced chemiluminescence substrate $(E C L)$ by following the manufacturer's instructions.

2. Aliquot ECL substrate into a 96 well plate $(100 \mu \mathrm{L} /$ well $)$ and insert the QDB plate inside the 96 well plate for 2 min under constant shaking.

3. Remove the QDB plate from the 96 well plate and shake briefly to remove the excess liquid. Place the plate onto a white microtiter plate.

4. Turn on the microplate reader, and select "plate with cover" on the user interface before placing the combined plates (QDB plate + white plate adaptor) inside the microplate reader for quantification.

Note: Make sure to use the white, non-transparent microtiter plate as an adaptor to avoid any interference from the plate. Make sure to choose "plate with cover" to avoid jamming the machine when combined plates (QDB plate+ 96 well plate adaptor) are placed inside the microplate reader.

\section{Representative Results}

The determination of the absolute amount of any protein including the CAPG protein in mouse tissue requires both a specific antibody and a purified protein as standard. The linear range of the analyses of both the protein standard and the lysates also needs to be established prior to any large-scale analysis. The linear range of the antibody is highly dependent on the antibody per se, and the appropriate dilution range of a specific antibody need to be verified by each individual user.

We first determined the specificity of the CAPG antibody in mouse kidney, spleen and prostate tissues using western blot analysis with the negative control (IgG free BSA) and positive control (commercially available CAPG protein) (Figure 1A). The anti-CAPG antibody was specific against lysates from mouse spleen, heart, muscle, and prostate (one band detected). Non-specific bands were observed in lysates from kidney and liver. However, in kidney lysate, the non-specific bands were significantly weaker than the specific band, which suggests the antibody is suitable for kidney tissue analysis. Next, the linear range of the protein standard and the amount of lysates for analyses were determined by two side by side dose curves. A commercially available CAPG protein was serially diluted as indicated in Table 1 based on our past experiences, and the tissue lysates of the mouse kidney, spleen and prostate were also diluted based on the amount of total protein in the lysates determined by a BCA total protein determination kit. Two dose studies were performed side by side and plotted together in Figure 1B. The appropriate amount of lysates of mouse kidney, spleen and prostate were chosen based on the QDB signals measured by the microplate reader in arbitrary unit. The original reading for this experiment is shown in Table 3.

In the last step, the serially diluted CAPG protein standard and the lysates from mouse kidney, spleen and prostate were loaded onto the QDB plate. In this case, we chose to load $0.3 \mu \mathrm{g} / \mathrm{sample}$ for lysates from mouse kidney and spleen and $1 \mu \mathrm{g} / \mathrm{sample}$ for lysates from mouse prostates analysis, as at these levels, the QDB reading was at least 20-fold over the background while well within the linear range of the analysis based on the dose curve of both the lysates and the protein standard. The plate was subjected to the described QDB protocol before the plate was quantified directly by the microplate reader. Using the serially diluted purified CAPG protein, we could establish a dose-response curve, the equation, and R2 by simple regression analysis using available software (e.g. Microsoft office excel). The QDB signals from lysates of mouse kidneys, spleens and prostates were converted to the absolute amount of CAPG protein in these lysates using the established equation, and the results were corrected by the total protein amount, in this case, $0.3 \mu \mathrm{g}$ for lysates from mouse spleens and kidneys, and $1 \mu \mathrm{g}$ for lysates from mouse prostates, for the final concentration of CAPG protein in these tissues as pg/ $\mu \mathrm{g}$. The results are shown in Figure $1 \mathrm{C}$ with the original reading shown in Table 4. 
A

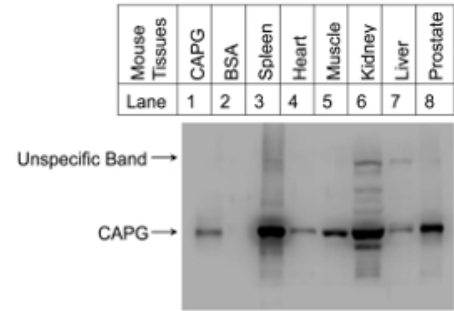

c

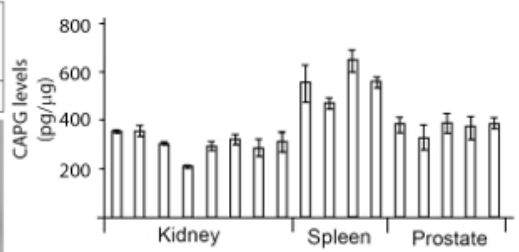

B

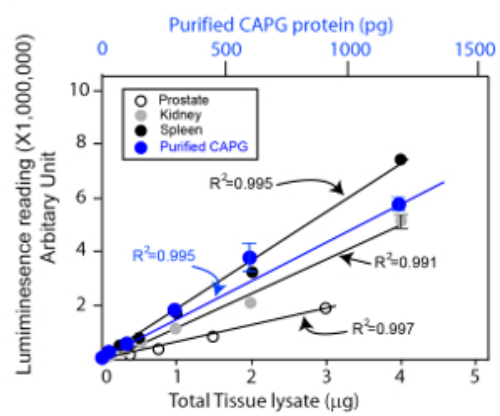

Figure 1. Representative result of a QDB analysis to determine the absolute CAPG levels in three mouse tissues (kidney, spleen and prostate). A. Examining the specificity of rabbit anti-CAPG antibody using mouse tissue lysates prepared from Spleen, Heart, Muscle, Kidney, Liver, and Prostate using western blot analysis with the negative control (IgG free BSA) and positive control (commercially available CAPG protein). B. defining the linear range of QDB analyses of rabbit anti-CAPG antibody using lysates prepared from prostate, kidney, spleen, and using purified recombinant CAPG protein standard. The results were an average of triplicates. C. Absolute determination of CAPG levels in lysates prepared from mouse kidneys, spleens, and prostates. Each bar represents one tissue from an individual mouse. The results were the average of triplicate. Please click here to view a larger version of this figure. 


\begin{tabular}{|c|c|c|c|c|c|c|c|c|}
\hline & amount & Reading1 & Reading2 & Reading 3 & average & fold & stdev & error bar \\
\hline \multirow[t]{2}{*}{$\begin{array}{l}\text { Recombinant } \\
\text { Human } \\
\text { CAPG }(\mathrm{pg})\end{array}$} & \multirow[b]{2}{*}{0} & \multirow[b]{2}{*}{25981} & \multirow[b]{2}{*}{10553} & \multirow[b]{2}{*}{37506} & \multirow[b]{2}{*}{24680} & \multirow[b]{2}{*}{1.00} & \multirow[b]{2}{*}{13523.52} & \multirow[b]{2}{*}{7807.81} \\
\hline & & & & & & & & \\
\hline & 3.703704 & 29632 & 28596 & 30575 & 29601 & 1.20 & 989.86 & 571.50 \\
\hline & 11.11111 & 61817 & 47021 & 50154 & 52997.3333 & 2.15 & 7797.04 & 4501.62 \\
\hline & 33.33333 & 175293 & 236104 & 185421 & 198939.333 & 8.06 & 32581.49 & 18810.93 \\
\hline & 100 & 529516 & 549739 & 504337 & 527864 & 21.39 & 22746.04 & 13132.43 \\
\hline & 300 & 1701716 & 1915987 & 1751499 & 1789734 & 72.52 & 112135.86 & 64741.67 \\
\hline & 600 & 4495282 & 3423830 & 3272489 & 3730533.67 & 151.16 & 666600.36 & 384861.89 \\
\hline & 1200 & 5988971 & 5497679 & 5676442 & 5721030.67 & 231.81 & 248662.56 & 143565.40 \\
\hline & 2400 & 12954799 & 12461900 & 11846610 & 12421103 & 503.29 & 555219.79 & 320556.29 \\
\hline & 4800 & 21640404 & 21364796 & 20037280 & 21014160 & 851.47 & 857152.75 & 494877.37 \\
\hline \multirow[t]{8}{*}{$\begin{array}{l}\text { kidney } \\
\text { lysate(ug) }\end{array}$} & 0 & 25981 & 10553 & 37506 & 24680 & 1.00 & 13523.52 & 7807.81 \\
\hline & 0.03 & 70661 & 76821 & 68634 & 72038.6667 & 2.92 & 4263.83 & 2461.72 \\
\hline & 0.1 & 120793 & 152293 & 123295 & 132127 & 5.35 & 17509.02 & 10108.84 \\
\hline & 0.25 & 387777 & 419033 & 367091 & 391300.333 & 15.85 & 26149.63 & 15097.50 \\
\hline & 0.5 & 687567 & 738537 & 567069 & 664391 & 26.92 & 88052.05 & 50836.88 \\
\hline & 1 & 1120404 & 953448 & 1381767 & 1151873 & 46.67 & 215886.58 & 124642.17 \\
\hline & 2 & 2090456 & 2352468 & 1948435 & 2130453 & 86.32 & 185270.46 & 106965.95 \\
\hline & 4 & 5358600 & 5562656 & 4701205 & 5207487 & 211.00 & 450167.54 & 259904.35 \\
\hline \multirow[t]{8}{*}{$\begin{array}{l}\text { spleen } \\
\text { lysate(ug) }\end{array}$} & 0 & 25981 & 10553 & 37506 & 24680 & 1.00 & 13523.52 & 7807.81 \\
\hline & 0.03 & 119973 & 119865 & 114253 & 118030.333 & 4.78 & 3271.71 & 1888.92 \\
\hline & 0.1 & 208024 & 261781 & 271043 & 246949.333 & 10.01 & 34026.94 & 19645.46 \\
\hline & 0.25 & 491712 & 616415 & 631879 & 580002 & 23.50 & 76851.33 & 44370.14 \\
\hline & 0.5 & 781815 & 809699 & 865119 & 818877.667 & 33.18 & 42403.71 & 24481.80 \\
\hline & 1 & 1692100 & 1776062 & 1687190 & 1718450.67 & 69.63 & 49953.24 & 28840.52 \\
\hline & 2 & 3139548 & 3183242 & 3389802 & 3237530.67 & 131.18 & 133668.29 & 77173.42 \\
\hline & 4 & 7277866 & 7229564 & 7789355 & 7432261.67 & 301.15 & 310193.50 & 179090.30 \\
\hline \multirow[t]{8}{*}{$\begin{array}{l}\text { prostate } \\
\text { lysate(ug) } \\
\end{array}$} & 이 & 25981 & 10553 & 37506 & 24680 & 1.00 & 13523.52 & 7807.81 \\
\hline & 0.046875 & 30443 & 28788 & 29241 & 29490.6667 & 1.19 & 855.28 & 493.80 \\
\hline & 0.09375 & 57619 & 31669 & 54116 & 47801.3333 & 1.94 & 14080.37 & 8129.31 \\
\hline & 0.1875 & 114439 & 122983 & 98179 & 111867 & 4.53 & 12600.44 & 7274.87 \\
\hline & 0.375 & 207244 & 222261 & 172198 & 200567.667 & 8.13 & 25690.58 & 14832.47 \\
\hline & 0.75 & 491996 & 471604 & 358876 & 440825.333 & 17.86 & 71698.87 & 41395.36 \\
\hline & 1.5 & 963910 & 884723 & 822231 & 890288 & 36.07 & 71003.25 & 40993.75 \\
\hline & 3 & 1882508 & 2147470 & 1920350 & 1983442.67 & 80.37 & 143306.42 & 82738.00 \\
\hline
\end{tabular}

Table 3: Result from microplate reader of the dose studies using both serially diluted, pooled lysates from mouse spleens, kidneys, and prostates and purified recombinant CAPG protein.

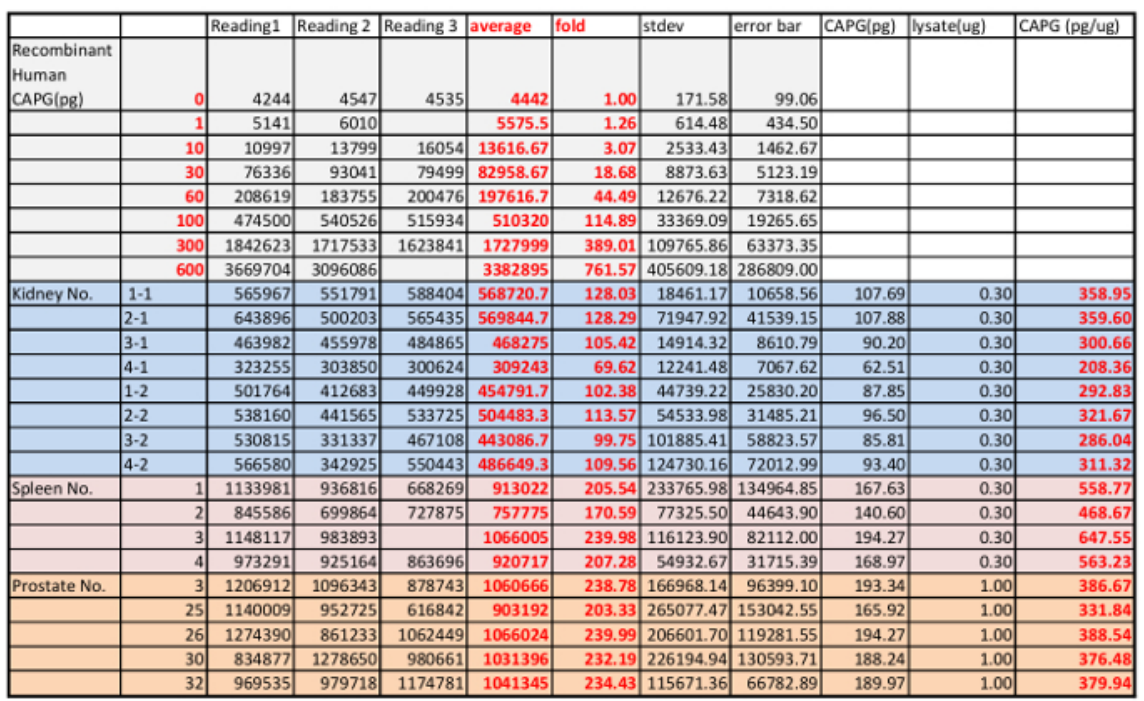

$Y=(X+49779) / 5743.6 \quad X$ is the reading from microplate reader

$Y$ is the CAPG content

Table 4: Result from microplate reader of the QDB analysis of the absolute CAPG level in mouse kidneys (8), spleens (4) and prostates (5) using a recombinant CAPG protein as standard. 


\section{Discussion}

Among all the current available immunoassay techniques of protein analysis except ELISA, QDB analysis is the only method to achieve absolute content of a specific protein at cellular and tissue levels in a high throughput format. Although with stable isotope-labeled standard, mass spectrometry is able to achieve absolute quantification of a few proteins, this method is not yet designed for high throughput performance. In this study, we demonstrated the process of QDB analysis to achieve absolute determination of CAPG protein level in mouse tissues including kidney, spleen, and prostate. CAPG levels were found to be between 200 to $360 \mathrm{pg} / \mathrm{g}$ in mouse kidney tissues, 460 to $650 \mathrm{pg} / \mathrm{g}$ in mouse spleens, and 330 to $390 \mathrm{pg} / \mathrm{g}$ in mouse prostate tissues.

Compared to ELISA, QDB analysis requires minimum efforts to be developed in a regular lab. First, the QDB plate is a based on a nitrocellulose membrane to eliminate the coating step in ELISA. Second, QDB analysis only requires one instead of two specific antibodies in a sandwich ELISA. Third, the high binding capacity of nitrocellulose membrane as compared to the ELISA plate surface also allows the membrane to withstand the stringent washing steps typically used in the immunoblot analysis to reduce the background interference. This feature is very useful in analyzing complicated lysates prepared from cells and tissues. In contrast, due to the relatively low binding capacity of ELISA plates, the reduction of the background when analyzing complicated cellular and tissue lysates becomes a real challenge in the developmental process.

QDB analysis can be adopted easily in any lab with the access of a specific antibody. However, it is important to mention that the specificity of the antibody is a relative term, limited by factors including the species, the tissue types and cell types. As shown in Figure 1A, CAPG antibody is specific when analyzing lysate from mouse kidney, spleen, and prostate, and yet becomes non-specific when analyzing mouse liver. In fact, we routinely found one antibody to be specific for one tissue type, but not always specific to other tissue type from the same species. Thus, prior western blot analysis is necessary to ensure the specificity of the QDB analysis. In fact, the relative specificity of the antibody may be the cause of false results often associated with ELISA analysis, as no matter how much effort the manufacturing company may have spent to ensure the specificity of the assay, they cannot exhaust all the possible types of samples the users may choose to analyze using their ELISA products.

As with all immunoassays, a potential problem with the QDB analysis method is the lack of consistency of the quality of the commercial antibody. Even if the apparent quality of an antibody from the same company (same catalog number, etc.) is used, there could be large differences from one purchase to another due to batch-to-batch variability. Therefore, unless full confidence is attained in the quality of the antibody available, recharacterizing the antibody upon every purchase is important.

In summary, we provide here a detailed protocol and an example when using the QDB analysis method to achieve absolute quantitative determination of a specific protein at the tissue level. We show that the QDB analysis method is a convenient tool for anyone who is interested in high throughput, quantitative immunoblot analysis. Its ability to achieve absolute determination of the content of a specific protein at a cellular and tissue level also distinguish this technique from traditional immunoblot techniques. This feature allows for the combination and comparison of results from multiple analyses, a step necessary especially in larger population studies, and the realization of relevant association studies at the protein level in the near future.

\section{Disclosures}

The authors Yunyun Zhang, Wenfeng Zhang and Jiandi Zhang are employees of Zestern Biotechniques that produces QDB plates used in this Article. Wenfeng Zhang and Yunyun Zhang declare conflict of interests, and Jiandi Zhang has filed patent applications. The others claim no competing interests.

\section{Acknowledgements}

This work is supported by Taishan Scholars Construction Engineering (G.T.), The Shandong Excellent Young Scientist Award (ZR2016JL026 to G. T.), National Natural Science Foundation of China (31771284, 3167070448, and 81641108), Shandong provincial natural science foundation (ZR2016JL026, 2017GSF18103), Shandong provincial science and technology Plan(J14LE01 and J15LK03), Yantai science and technology plan(2015ZH083) and Binzhou Medical University Scientific Research Funds (BY2013KYQD17, BY2013KYQD18), the Swedish Research Council grant 621-2011-4423 and 2015-4870. This work is also sponsored by "Yantai Double Hundred Talent Plan" and "Yantai Hi-Tech Zone Blue Ocean Talent Plan".

\section{References}

1. Renart, J., Reiser, J., \& Stark, G. R. Transfer of proteins from gels to diazobenzyloxymethyl-paper and detection with antisera: a method for studying antibody specificity and antigen structure. Proc Natl Acad Sci U S A. 76 (7), 3116-3120 (1979).

2. Burnette, W. N. "Western blotting": electrophoretic transfer of proteins from sodium dodecyl sulfate--polyacrylamide gels to unmodified nitrocellulose and radiographic detection with antibody and radioiodinated protein A. Anal Biochem. 112 (2), 195-203 (1981).

3. Towbin, H., Staehelin, T., \& Gordon, J. Electrophoretic transfer of proteins from polyacrylamide gels to nitrocellulose sheets: procedure and some applications. Proc Natl Acad Sci U S A. 76 (9), 4350-4354 (1979).

4. Uhlen, M. et al. A proposal for validation of antibodies. Nat Methods. 13 (10), 823-827 (2016).

5. Hawkes, R., Niday, E., \& Gordon, J. A dot-immunobinding assay for monoclonal and other antibodies. Anal Biochem. 119 (1), $142-147$ (1982).

6. Engvall, E., \& Perlmann, P. Enzyme-linked immunosorbent assay (ELISA). Quantitative assay of immunoglobulin G. Immunochemistry. 8 (9), 871-874 (1971).

7. Engvall, E., Jonsson, K., \& Perlmann, P. Enzyme-linked immunosorbent assay. II. Quantitative assay of protein antigen, immunoglobulin G, by means of enzyme-labelled antigen and antibody-coated tubes. Biochim Biophys Acta. 251 (3), $427-434$ (1971). 
8. Paweletz, C. P. et al. Reverse phase protein microarrays which capture disease progression show activation of pro-survival pathways at the cancer invasion front. Oncogene. 20 (16), 1981-1989 (2001).

9. Tibes, R. et al. Reverse phase protein array: validation of a novel proteomic technology and utility for analysis of primary leukemia specimens and hematopoietic stem cells. Mol Cancer Ther. 5 (10), 2512-2521 (2006).

10. Solier, C., \& Langen, H. Antibody-based proteomics and biomarker research - current status and limitations. Proteomics. 14 (6), $774-783$ (2014).

11. Tian, G. et al. Quantitative dot blot analysis (QDB), a versatile high throughput immunoblot method. Oncotarget. 8 (35), $58553-58562$ (2017). 